\title{
COMPARATIVE PATTERNS OF GROWTH AND DEVELOPMENT IN CRICETINE RODENTS AND THE EVOLUTION OF ONTOGENY
}

\author{
G. Ken Creighton ${ }^{1}$ and Richard E. Strauss \\ Museum of Zoology and Division of Biological Sciences, \\ University of Michigan, Ann Arbor MI 48109
}

\begin{abstract}
The quantitative description of growth curves for morphometric traits provides a basis for assessing the ontogenetic patterns underlying differences in morphological structure, as demonstrated with comparisons among neotomine-peromyscine rodents. Morphometric differences among contemporary rodent species are shown to result from relatively simple changes in relative growth rates and timing. Quantitative ontogenetic studies add a dynamic component to the assessment of morphological similarity, thus providing a more robust procedure for detecting homoplasy than static comparison of adult morphology. Applying the principles of phylogenetic systematics to studies of developmental timing among closely related taxa may be a useful and informative complement to studies based on molecular similarity or static comparison of adult morphology. Interspecific and intraspecific differences in allometric scaling of anatomical structures may reflect differences in growth patterns among the taxa compared; caution is warranted in inferring patterns of genetic correlation from data on phenotypic scaling.
\end{abstract}

\section{Received March 12, 1984. Accepted July 16, 1985}

Contemporary and traditional classifications of higher vertebrates are based in large part on assessments of similarity in adult structure of living and fossil forms. Two assumptions underlie all inferences about patterns of relationships based on comparative evidence, whether the basis of comparison is phenetic (based on overall similarity) or phylogenetic (based on derived similarity or synapomorphy) and whether the data are morphological or molecular. The first assumption is that degree of phenotypic similarity is related to degree of genetic similarity. Though perhaps sustainable for some primary gene products and macromolecules (such as hemoglobins and cytochromes), this is largely untested for most complex structures in vertebrates and may be difficult to test in principle (Dawid et al., 1982; Lewontin, 1984). An observed lack of correlation in some cases has caused problems for systematists and evolutionary biologists (e.g., Turner, 1974; Schnell et al., 1978; Lessios, 1981).

The second assumption is that simi-

\footnotetext{
${ }^{1}$ Current address: The Nature Conservancy, International Program, 1785 Massachusetts Avenue, N.W., Washington, DC 20036.
}

larity in adult morphology reflects similarity in the underlying patterns and processes of development (Bonner and Horn, 1982). This presumption of developmental conservatism is more amenable to study (at the gross morphological level) with contemporary techniques. We can describe and evaluate differences in size and shape of morphological features in terms of relative rates and timing of growth in an appropriate number of morphological dimensions. What is required is a method of describing growth in terms of individual ontogenies that can be used to affect comparisons among a broad enough range of taxa to be interesting and informative.

We present here a quantitative analysis of patterns of growth and development in a suite of five morphometric traits and four "discrete" developmental landmarks for 13 species (eight genera) of North American cricetine rodents. That differences in size and shape of homologous structures in different taxa result from differences in rates and timing of growth and development is axiomatic (Alberch, 1980). In providing quantitative descriptions of age-specific growth patterns, however, we will show how similarity in size and shape of adult mor- 
phological features may arise from different patterns of development and assess the degree to which differences in "control parameters" (sensu Alberch et al., 1979; Alberch, 1980) underlie the observed diversity in adult morphology. Subsequently, we will summarize differences in the relative timing of development of various traits among these rodents, outline a program for using such data to estimate phylogenetic relationships among them, and compare the phylogeny estimated from comparative ontogenetic data with alternatives estimated from more traditional studies based on static comparison of adult morphology. Finally, we show how differences in the relative rates and timing of growth in various traits (e.g., brain and body weights) may account for the patterns of static allometry observed in some intraspecific and interspecific comparisons.

\section{MATERIALS AND Methods}

\section{The Quantitative Description of Growth}

Data.-Our study is based on longitudinal data reported in the literature for 13 species of neotomine-peromyscine rodents, representing eight of the 18 genera recognized by Carleton (1980) (Table 1). We included all species of neotomineperomyscine rodents for which complete data sets were available. In addition, we included, for comparison, data on two other species of rodents: Perognathus longimembris (Heteromyidae) and Rattus exulans (Murinae).

Complete data sets included information on postnatal growth in five metric features: body weight (W), head and body length (HBL), tail length (TL), hind foot length (HFL), and ear length (EL). Data were reported in the literature as means for a study sample, measured at weekly intervals or less, for at least the period from birth to eight weeks of age (e.g., Fig. 1). Obviously many factors, such as litter size, age and condition of the mother, differential mortality of smaller young, and laboratory conditions, influence the growth rates of individual young (Myers and Master, 1983), but the mean values approximate the general pattern of growth in these features for a typical individual of a given taxon. Indeed, studies of "targeted" growth (Tanner, 1963) in rodents (Riska et al., 1984; Atchley, 1984) and of heritabilities of growth parameters (Eisen, 1975; Herbert et al., 1979; Kidwell et al., 1979) indicate that growth rates may be tightly regulated about this average, converging on a very restricted range of adult phenotypes within a population. Estimates of adult size were based either on measurements of wild-caught specimens (generally the parents of the sample) or on the asymptotic size calculated from the growth curves for a particular sample (Fig. 1). Unlike some murid rodents, neotomine-peromyscines exhibit no detectable sexual dimorphism in any of the traits studied (Carleton, 1980), so samples included both male and female young.

Data were also recorded on the mean length of the gestation period and on the timing of three "discrete" developmental events: eye opening, ear opening, and eruption of the lower incisors. We recognize that the characterization of these latter events as discrete is arbitrary in that they represent recognizable points along a developmental continuum; we use the term merely to imply a repeatably and unambiguously observable landmark in the development of an animal. These events also correspond with significant phases in the life history of rodents, such as attainment of the abilities to orient to their environment acoustically or visually and to process solid food.

Analytical Methods. -Comparison of data on growth and development among taxa requires a model for describing growth that is sufficiently precise to characterize individual trajectories, yet sufficiently flexible to facilitate inter-taxon comparisons. The parameters required to describe and compare patterns of postnatal growth in a given trait, such as body weight, are shown in Figure 2. Our formalism and terminology are generally consistent with Alberch et al. (1979). 
TABle 1. Taxa, sample sizes, adult body weight, and literature references for data on growth and development in rodents.

\begin{tabular}{lccl}
\hline \multicolumn{1}{c}{ Taxon } & $N^{\mathrm{a}}$ & Weight (g) & \multicolumn{1}{c}{ References } \\
\hline Cricetinae & & & \\
Neotoma albigula & $4-11$ & $149.2^{\mathrm{b}}$ & Richardson, 1943 \\
Ochrotomys nuttalli & 8 & $18.3^{\mathrm{c}}$ & Layne, 1960 \\
Ototylomys phyllotis & 86 & $65.5^{\mathrm{b}}$ & Helm, 1975 \\
Peromyscus leucopus castaneus & $11-158$ & $21.9^{\mathrm{b}}$ & Lackey, 1973 \\
Peromyscus leucopus noveboracensis & $80-185$ & $19.6^{\mathrm{b}}$ & Lackey, 1973 \\
Peromyscus maniculatus bairdid & 39 & $15.5^{\mathrm{b}}$ & Svihla, 1935 \\
Peromyscus maniculatus artemisiae & $14-63$ & $21.3^{\mathrm{c}}$ & Svihla, 1934 \\
Peromyscus melanocarpus & $21-41$ & $59.0^{\mathrm{b}}$ & Rickart, 1977 \\
Peromyscus mexicanus & $7-17$ & $60.5^{\mathrm{b}}$ & Rickart, 1977 \\
Peromyscus yucatanicus & $45-108$ & $28.6^{\mathrm{b}}$ & Lackey, 1976 \\
Podomys floridanus & 20 & $27.3^{\mathrm{c}}$ & Layne, 1966 \\
Reithrodontomys humulis & $7-20$ & $6.0^{\mathrm{b}}$ & Layne, 1959 \\
Scotinomys tequina & $93-140$ & $14.8^{\mathrm{b}}$ & Hooper and Carleton, 1976 \\
Scotinomys xerampelinus & $44-80$ & $14.7^{\mathrm{b}}$ & Hooper and Carleton, 1976 \\
Tylomys nudicaudus & 9.5 & $284.3^{\mathrm{b}}$ & Helm, 1973 \\
Heteromyidae & & & \\
Perognathus longimembris & 26 & $8.2^{\mathrm{b}}$ & Hayden and Gambino, 1966 \\
Murinae & & & \\
Rattus exulans & $7-28$ & $73.0^{\mathrm{c}}$ & Wirth, 1973 \\
\hline a & & &
\end{tabular}

a Minimum and maximum sample sizes for each age interval from birth to 8 weeks.

Weight of lab-raised specimens at last age recorded.

${ }^{c}$ From wild-caught specimens.

d Additional data from Dice and Bradley (1942) and Layne (1968).

However, our descriptions of ontogeny are grounded in a quantitative, generalized model of negative exponential growth (von Bertalanffy, 1960; Laird, 1965) (Fig. 2A). In this model $\alpha$ represents the time of onset of growth (or birth, in our study); $S_{\alpha}$ is size at birth; $\beta$ is defined as the age (time since birth) at which $90 \%$ of exponential growth (Laird, 1965) has occurred; $S_{\beta}$ is that corresponding size; and $S_{\mathrm{A}}$ is the asymptotic (adult) size at the end of the period during which growth approximates a negative exponential curve. $\bar{K}$ is the average growth rate over the interval from birth $(\alpha)$ to $90 \%$ adult size $(\beta)$. A consistent notation is used to describe growth trajectories of the other traits; for example, $\mathrm{HBL}_{\beta}$ is $90 \%$ of adult $\mathrm{HBL}$ while $\beta_{\mathrm{HBL}}$ is the age at which that size is attained (Fig. 2B). When the model holds for a given morphometric trait, these few parameters provide a complete and precise description of postnatal growth. The difference in adult size between any two forms in a particular trait can be accounted for, or partitioned, in terms of three parameters: size at birth $\left(S_{\alpha}\right)$; growth rate $(\bar{K})$; and the length of the growth interval $(\beta-\alpha)$.

Choosing $90 \%$ of asymptotic size to represent $\beta$, or a comparable point such as $95 \%$ or $99 \%$, provides a landmark from within the range of observed data that indicates the age at which a constant proportion of total exponential growth has occurred. When the data are well fit by a negative exponential model there exists a unique function that describes the trajectory through the points $\left(\alpha, S_{\alpha}\right),\left(\beta, S_{\beta}\right)$ with an asymptote at $S_{\mathrm{A}}$, so that we can represent the curvilinear growth trajectory with a straight line segment of slope $\bar{K}$ (the average growth rate, Fig. $2 \mathrm{~A}$ ) with no loss of information.

Negative exponential growth curves were fit to the data using a robust nonlinear regression procedure that involves fitting the model exactly to all possible subsets of three data points and selecting the medians of the parameter distributions thus generated. This is a modified jackknifing (subsetting) technique which 


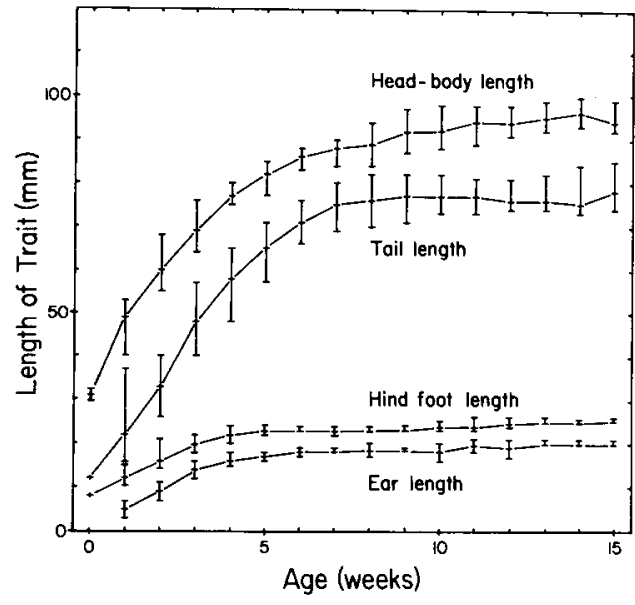

FIG. 1. Growth of four linearly measured traits from birth through 15 weeks of age for Peromyscus (Podomys) floridanus. Bars indicate range of measurements at each age. $N=20$. Redrawn from Layne (1966).

i) yields approximate maximum-likelihood estimates of the explicit parameters of the von Bertalanffy model $\left(t_{0}, S_{\mathrm{A}}, k\right)$; ii) provides comparable estimates of additional, biologically important descriptive parameters (such as $\alpha, \beta, S_{\alpha}$, and $S_{\beta}$ ); and iii) provides robust estimates of the sampling errors of these parameters and of the covariances among them. Thus we can describe each ontogenetic trajectory by a few biologically interpretable descriptive characteristics for which we also have estimates of variances and covariances.

In the same way that we describe growth curves for individual traits, we can evaluate and compare the ontogenetic trajectories of multivariate vectors computed from some combination of logically or functionally related features. We represent "general size" in our comparisons by a vector summarizing the joint size increase in all morphometric traits (Jolicoeur, 1963; Leamy and Bradley, 1982). Our general-size vector is the major axis (first principal component, PC I) calculated from the covariance matrix of log-transformed mean values for each age sample, representing the interval from
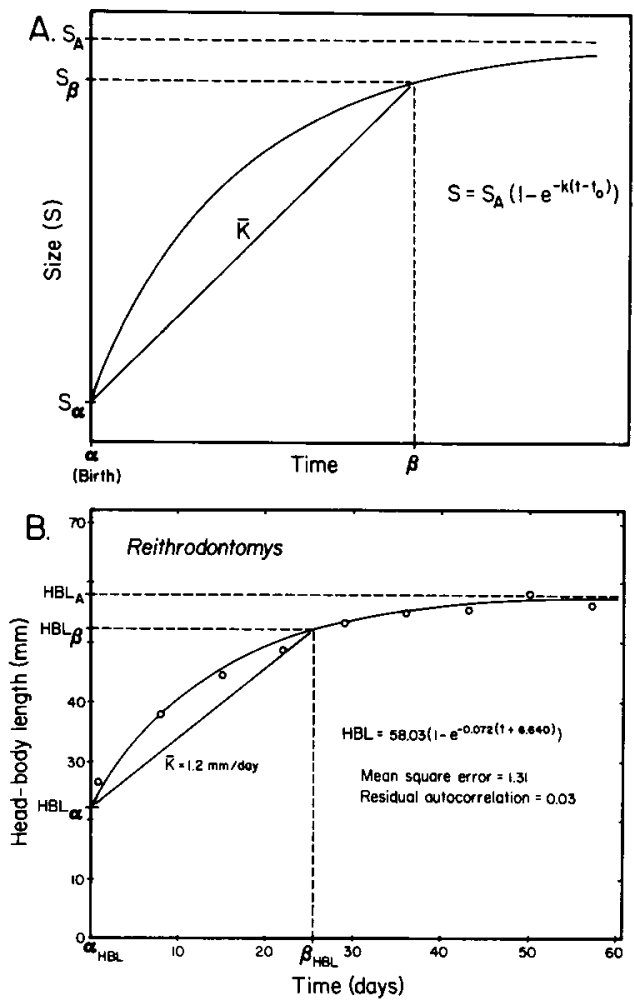

FIG. 2. A) Descriptive parameters for generalized negative exponential (Bertalanffy) growth curve (see text for discussion). B) Fitted postnatal growth curve, corresponding equation, and statistics of fit for head and body length (HBL) of Reithrodontomys humulis.

birth to eight weeks of age. This vector provides a convenient and consistent measure of overall size and provides a standard measure against which growth in individual traits can be compared. A measure of the equivalence of the size vectors among taxa is provided by the coefficients of vector correlation (Cheverud, 1982) for pairwise comparisons of taxa. This statistic is the cosine of the angle between each vector pair, calculated as the inner product of the loadings (Morrison, 1976). For normalized vectors (or those roughly equal in scale), this value equals unity when the vectors are parallel and zero when they are orthogonal. Among the 15 taxa vector correlations ranged from 0.972 to 0.999 , in- 

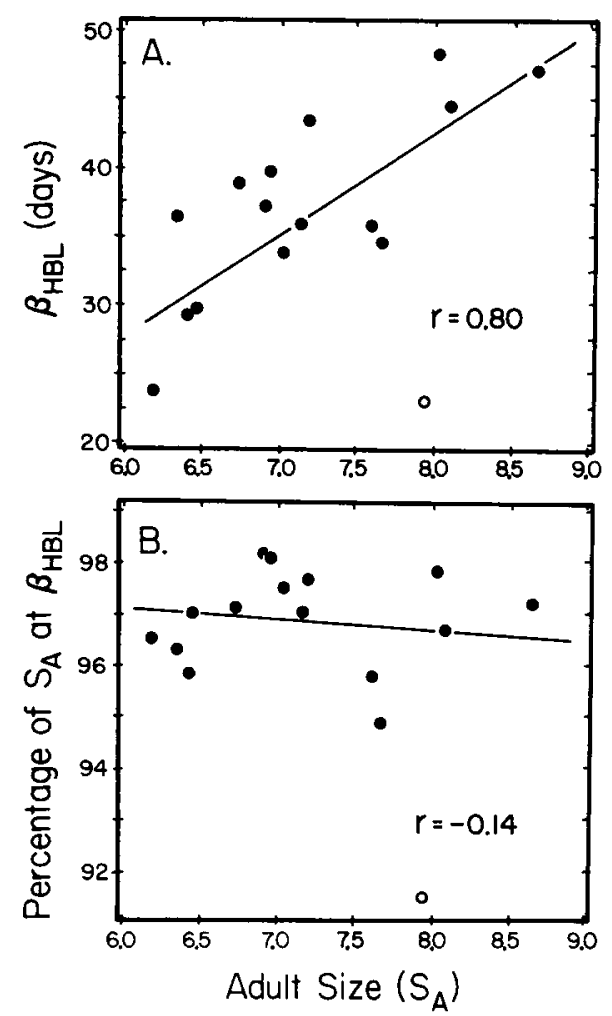

FIG. 3. The relationship between the A) absolute and $B$ ) relative timing of growth in head and body length (HBL) for 16 rodent taxa from Table 2. A) The age $\beta_{\mathrm{HBL}}$ as a function of general adult size $\left(S_{\mathrm{A}}\right.$ based on within-group PC I). B) The percentage of adult size $\left(S_{\mathrm{A}}\right)$ attained at time $\beta_{\mathrm{HBL}}$, as a function of adult size. Data from Table 2. Open circles represent Ototylomys phyllotis.

dicating relatively high consistency for this measure of overall size.

\section{RESUlts AND Discussion \\ Differences in Growth Patterns Among Species}

The absolute duration of growth in most traits surveyed for these rodents is strongly correlated with body size (e.g., Fig. 3A); larger rodents, in general, take longer than smaller rodents to reach adult size. However, the relative timing of particular traits (expressed in terms of proportion of general adult size) is mostly independent of body size (Fig. 3B). Relative timing of growth in head and body
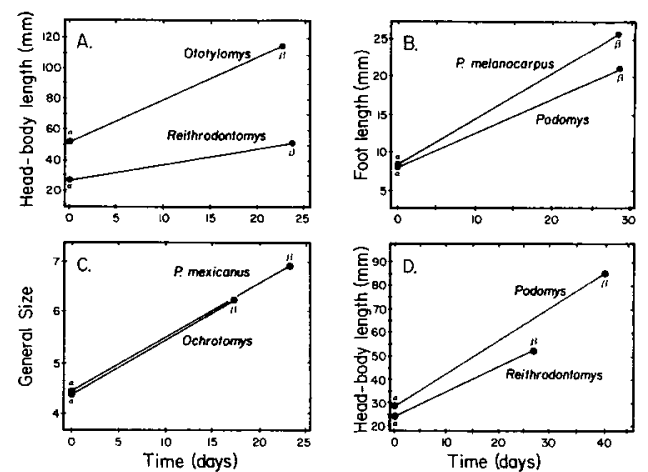

FIG. 4. Pairwise comparisons of postnatal growth in several measurements. A) Difference in size at birth and postnatal growth rate in head and body length (HBL) for Ototylomys phyllotis and Reithrodontomys humulis. B) Difference in postnatal growth rates for foot length between Peromyscus melanocarpus and Podomys floridanus. C) Difference in duration of growth in general size (within-group PC I) between Peromyscus mexicanus and Ototylomys nuttalli. D) Difference in size at birth, average growth rate, and duration of growth in HBL for $P$. floridanus and $R$. humulis.

length (HBL), for example, is not related to overall size among these taxa, as indicated by the lack of any significant relationship between absolute adult size and the proportion of adult size $\left(S_{\mathrm{A}}\right)$ at which $\mathrm{HBL}_{\beta}$ is attained.

Differences among taxa in the relative adult size of a given feature may result from three general types of ontogenetic differences: differences in size at birth (Fig. $4 \mathrm{~A})$; differences in average growth rates (Fig. 4B); differences in the duration of the geometric growth phase (Fig. 4C); or some combination of these (Fig. 4D). The terminology of Alberch et al. (1979) can be used to describe these differences in growth pattern. Figure 4A illustrates a situation ("displacement") in which adult differences are influenced primarily by the timing of onset of exponential growth. Figure 4B illustrates the consequences in terms of adult morphology of differences in relative growth rates only, to which the terms "acceleration" or "neoteny" would apply depending on the phylogenetic context (Fink, 1982). In Figure 4C, changes in the timing of offset (duration) 


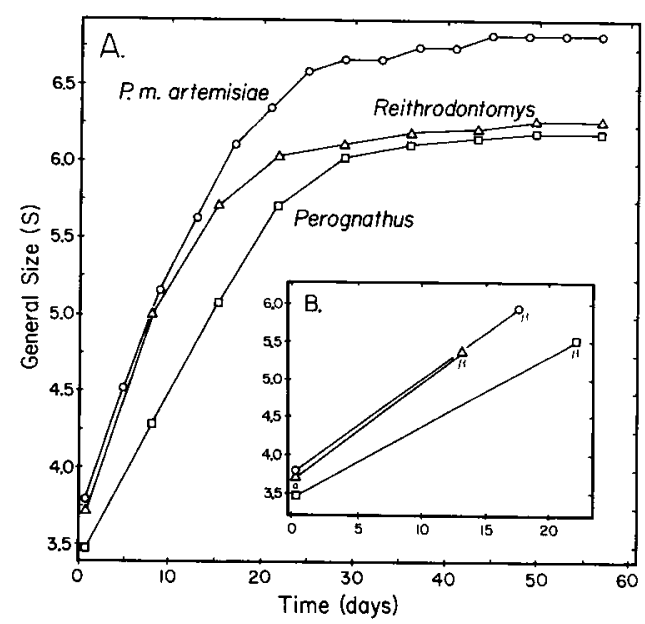

FIG. 5. A) Growth curves for multivariate size estimates $(S)$ for Peromyscus $m$. artemisiae, Reithrodontomys humulis, and Perognathus longimembris. B) Average growth rates $(\bar{K})$ from birth $(\alpha)$ to $\beta$ for the same taxa.

of growth result in morphological differences attributable to "progenesis" or "hypermorphosis," again depending on the phylogenetic context. The difference in HBL between adult Podomys floridanus and Reithrodontomys humulis (Fig. 4D) is due to composite differences in the prenatal ontogeny, postnatal growth rate, and duration of growth. It is perhaps best characterized by direct comparison of the growth trajectories. We can partition the difference in HBL between these taxa into three components: difference in prenatal ontogeny $(\Delta \alpha)$, postnatal growth rate $(\Delta \bar{K})$, and duration of growth $(\Delta \beta)$. Comparing growth patterns in this way is useful for understanding the way selection may have operated on various aspects of growth to effect differences in adult morphology.

The comparison of growth in overall size (within-group PC I score) among the three taxa illustrated in Figure 5 shows both convergence ( $R$. humulis vs. Perognathus longimembris) and divergence (Peromyscus $m$. artemisiae vs. $R$. humulis) in body size during postnatal development. Again, differences in adult size among these taxa can be partitioned into differences due to prenatal ontogeny,
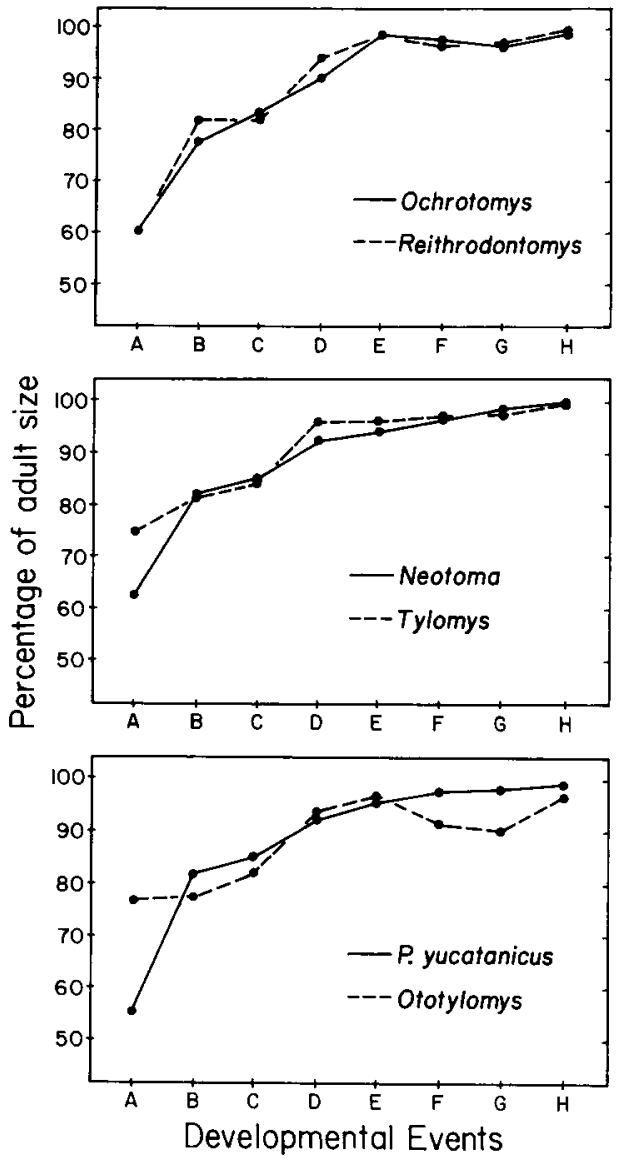

FIG. 6. Pairwise comparisons of relative timing of developmental events during ontogeny. Events (A-H) are from Table 2. Lower-incisor eruption was not used due to incomplete data.

postnatal growth rate, and duration of growth. Such differences might reflect relatively recent selection on life history traits (such as length of gestation) or may represent differences due to phylogenetic history.

We have seen that, while the absolute duration of growth in these traits is strongly correlated with body size, relative timing (expressed in terms of proportion of adult size) varies independently of body size. To compare overall developmental patterns, we plotted the percentage of general adult size $(S)$ at which each of eight developmental "events" or landmarks occurred for sev- 
TABLE 2. Relative timing of nine developmental landmarks expressed in terms of percentage of adult size $\left(S_{A}\right)$. Standard deviations (SD) and coefficients of variation (CV) are based on arcsine-transformed proportions.

\begin{tabular}{|c|c|c|c|c|c|c|c|c|c|}
\hline \multirow[b]{2}{*}{ Taxon } & \multicolumn{9}{|c|}{ Developmental landmarks } \\
\hline & $\begin{array}{l}\text { Birth } \\
\text { (A) }\end{array}$ & $\begin{array}{l}\text { Auditory } \\
\text { meatus } \\
\text { open } \\
\text { (B) }\end{array}$ & $\begin{array}{l}\text { Eyes } \\
\text { open } \\
\text { (C) }\end{array}$ & $\begin{array}{c}\beta \\
\text { foot } \\
\text { length } \\
\text { (D) }\end{array}$ & $\begin{array}{c}\beta \\
\text { ear } \\
\text { length } \\
\text { (E) }\end{array}$ & $\underset{(\mathrm{F})}{\stackrel{\beta}{\beta}}$ & $\begin{array}{c}\beta \\
\text { tail } \\
\text { length } \\
(\mathrm{G})\end{array}$ & $\begin{array}{c}\beta \\
\mathrm{wt} \\
(\mathrm{H})\end{array}$ & $\begin{array}{l}\text { Lower- } \\
\text { incisor } \\
\text { eruption }\end{array}$ \\
\hline $\begin{array}{l}\text { Neotoma albigula } \\
\text { Ochrotomys nuttalli }\end{array}$ & $\begin{array}{l}62.5 \\
60.5\end{array}$ & $\begin{array}{l}82.0 \\
78.0\end{array}$ & $\begin{array}{l}88.8 \\
83.8\end{array}$ & $\begin{array}{l}92.5 \\
90.6\end{array}$ & $\begin{array}{l}94.0 \\
98.8\end{array}$ & $\begin{array}{l}96.6 \\
98.1\end{array}$ & $\begin{array}{l}99.3 \\
96.9\end{array}$ & $\begin{array}{l}99.9 \\
99.3\end{array}$ & $\overline{70.0}$ \\
\hline Ototylomys phyllotis & 76.7 & 77.0 & 81.3 & 93.6 & 96.6 & 91.4 & 90.2 & 97.0 & $0.0^{\mathrm{a}}$ \\
\hline Peromyscus l. castaneus & 56.8 & 79.0 & 81.2 & 93.4 & 95.9 & 98.2 & 98.1 & 99.6 & 65.0 \\
\hline Peromyscus l. noveboracensis & 56.8 & 80.0 & 83.4 & 94.8 & 95.8 & 97.5 & 97.6 & 99.3 & 67.0 \\
\hline Peromyscus maniculatus & 53.5 & 78.3 & 84.3 & 94.6 & 94.8 & 95.8 & 98.7 & 99.6 & 68.0 \\
\hline Peromyscus melanocarpus & 54.7 & 85.0 & 89.1 & 92.9 & 95.9 & 95.7 & 99.2 & 99.5 & 77.0 \\
\hline Peromyscus mexicanus & 56.9 & 83.0 & 86.1 & 93.1 & 96.1 & 94.8 & 98.7 & 99.9 & 76.0 \\
\hline Peromyscus yucatanicus & 55.2 & 82.0 & 85.3 & 92.1 & 95.9 & 97.6 & 98.2 & 99.5 & 72.0 \\
\hline Podomys floridanus & 52.6 & 80.0 & 85.8 & 94.6 & 94.8 & 97.0 & 98.6 & 99.2 & - \\
\hline Reithrodontomys humulis & 59.9 & 82.0 & 82.1 & 94.2 & 98.9 & 96.5 & 97.4 & 99.7 & 77.0 \\
\hline Scotinomys tequina & 57.8 & 84.0 & 86.1 & 93.6 & 96.8 & 97.0 & 98.0 & 99.7 & - \\
\hline Scotinomys xerampelinus & 59.2 & 84.0 & 84.2 & 92.9 & 96.5 & 97.1 & 97.9 & 99.2 & - \\
\hline Tylomys nudicaudus & 74.5 & 81.0 & 83.5 & 96.1 & 96.1 & 97.1 & 97.8 & 99.4 & $0.0^{\mathrm{a}}$ \\
\hline Perognathus longimembris & 50.6 & 81.0 & 81.4 & 92.0 & 95.0 & 96.3 & 95.4 & 98.2 & - \\
\hline Rattus exulans & 59.0 & 77.0 & 80.4 & 94.3 & 94.5 & 97.5 & 97.7 & 99.5 & 71.0 \\
\hline SD & 4.3 & 1.8 & 2.1 & 1.6 & 2.3 & 2.3 & 3.2 & 2.0 & 2.8 \\
\hline CV $(\%)$ & 8.5 & 2.9 & 3.1 & 2.1 & 2.9 & 2.8 & 3.9 & 2.4 & 4.9 \\
\hline Number of taxa & 16 & 16 & 16 & 16 & 16 & 16 & 16 & 16 & 9 \\
\hline
\end{tabular}

a Erupted at birth (Helm, 1973).

eral pairwise comparisons (Table 2, Fig. 6). This type of plot provides a convenient visual summary of similarities and contrasts between the patterns of relative developmental timing among taxa, independent of body size. The ordering of events (A through $\mathrm{H}$ of Table 2) was assigned to be the ontogenetic sequence observed in Rattus exulans, a murid rodent outside of the primary study group. This ordering is consistent with the most common ontogenetic sequence within the neotomine-peromyscines.

The relative amount of variation in relative timing of the eight developmental events and landmarks is summarized in Table 2. Size at birth exhibits the largest amount of variation, likely reflecting differences in absolute and relative gestation lengths. The factors affecting the tradeoff between the proportion of total developmental time spent in utero vs. ad mamma are likely to be complex, involving relative risks of predation to pregnant females and nestlings, structur- al limitations (e.g., pelvic breadth) on size of young at birth, and other ecological and physiological compromises.

\section{Inferring Phylogeny from Quantitative Ontogenetic Data}

Developmental patterns, like other aspects of the phenotype of contemporary organisms, have an historical component; that is, they may reflect (in part) the evolutionary history of the animals studied. The data of Table 2 comprise a matrix of information on similarities and differences in developmental patterns analogous to a matrix of characters used in conventional taxonomic studies. To evaluate the pattern of phylogenetic relationships implied by these data on relative timing, we computed a Wagner network (Kluge and Farris, 1969; Farris, 1970) (Fig. 7A) and rooted it based on the conclusions of Carleton (1980) (Fig. 7B). This network of similarity in developmental timing can be viewed as an hypothesis of phylogenetic relationship 
among the neotomine-peromyscines. The numbers plotted on the tree identify parsimonious locations of switches or reversals in the relative order of occurrence of two developmental events.

When taken at face value, these data on heterochrony show a moderate degree of homoplasy comparable to most traditional morphological data sets. Considering only the relative order of occurrence of discrete developmental landmarks gives a consistency index (Farris, 1970) of 0.5 . This low level of fit, however, is primarily an artifact of characterizing reversals in an arbitrary, typological manner: reversals were identified as switches in the relative order of occurrence of two landmarks without regard to the type of change in developmental pattern (acceleration, displacement, etc.) underlying a particular reversal in relative timing. By referring back to the original growth trajectories for the quantitative characters, it is possible to evaluate the processes underlying a particular switch in timing.

In Figure 8, for example, we show the growth trajectories for head and body length (HBL) and ear length (EL) for six taxa. The presumed plesiomorphic condition, inferred from outgroup comparison, is for EL to reach adult size before HBL. In comparing the trajectories of postnatal growth in EL and HBL we see that two different processes underlie the "reversal" of relative timing that characterizes Ototylomys phyllotis on the one hand, and Peromyscus mexicanus and $P$. melanocarpus on the other. In the case of $O$. phyllotis, the relative growth rate in EL is lower than in the other taxa, while the relative rate of growth in HBL is unchanged. In $P$. mexicanus and $P$. melanocarpus, relative growth rate in EL is about the same as for the other taxa while growth in HBL is relatively accelerated. In one case, then, the reversal is due to a change in the relative growth rate of ear length, while in the other the switch is due to a change in the timing of growth in HBL. This example illustrates the special advantage of quantitative characters in phylogenetic studies, in
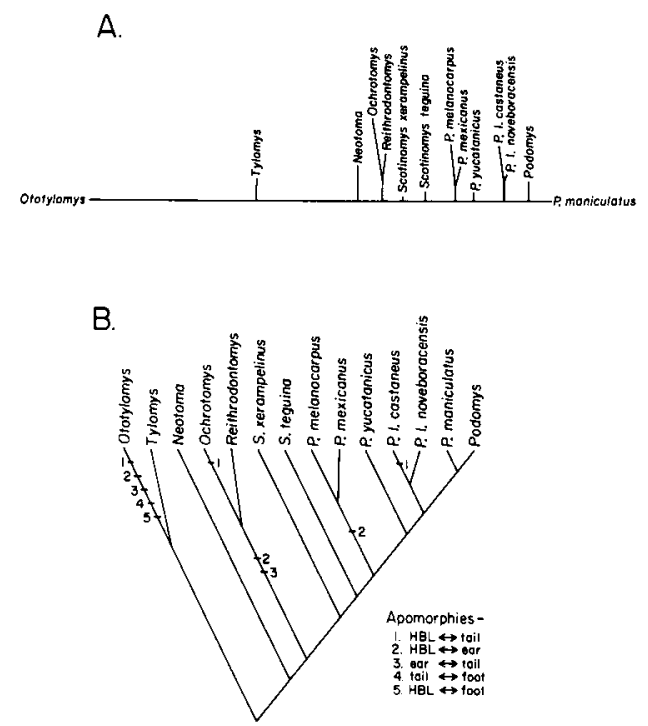

FIG. 7. A) Wagner network calculated for fourteen neotomine-peromyscines from the matrix of data on relative timing of developmental landmarks (Table 2). Lengths of internodes are drawn proportional to patristic distance (Kluge and Farris, 1969). B) Topology of the Wagner network rooted between Tylomys and Neotoma, following Carleton (1980). The numbers represent the parsimonious location of reversals in the relative timing of the landmarks identified compared to the plesiomorphic or ancestral sequence inferred by outgroup comparison.

that, by following the growth trajectories of such characters, it is possible to discern differences in rate and timing of growth processes that underlie the patterns of phenotypic similarity implied by a phylogenetic hypothesis. In the above example, the reversal in relative timing of growth in ear length and head and body length that characterizes $P$. mexicanus and $P$. melanocarpus is parsimoniously interpreted as a shared derived state, while the reversal characterizing $O$. phyllotis is interpreted as a "convergent" similarity. The processes underlying the two reversals are different.

The Wagner network (Fig. 7A) provides an overview of similarity and contrasts in overall developmental patterns. The topology (Fig. 7B) corresponds in major outline with previous studies based 

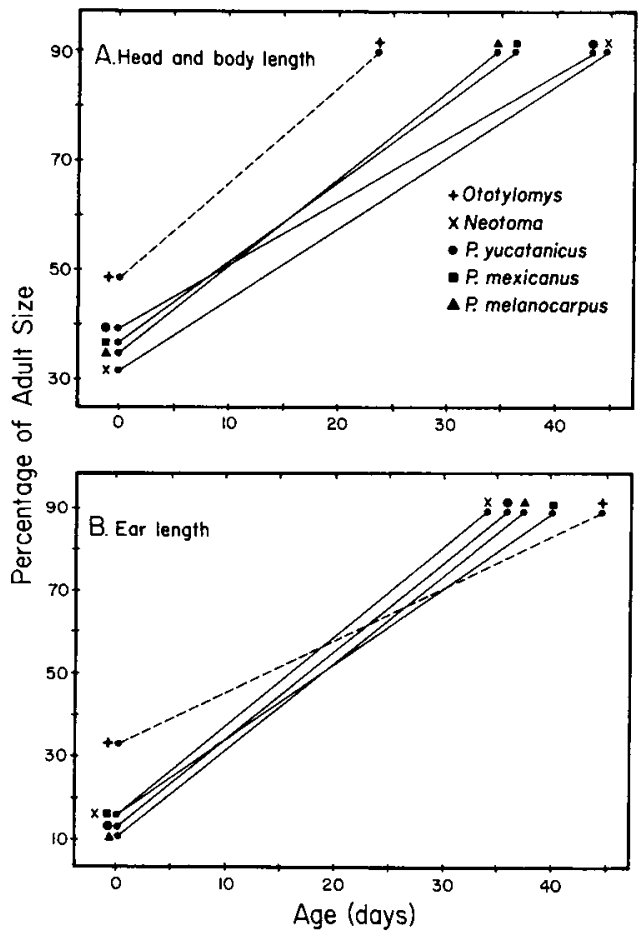

FIG. 8. Average growth rates $(\bar{K})$ from birth $(\alpha)$ to $\beta$ for $A$ ) head and body length and $B$ ) ear length, for six neotomine-peromyscine taxa. See text for discussion.

on conventional morphological comparison (Fig. 9), but differs in some details. As in Carleton's (1980) study, Ototylomys and Tylomys are highly divergent from the other neotomine-peromyscines. In fact, they are more different from the other taxa than is the Pacific murid, Rattus exulans. Hooper (1960), Hooper and Musser (1964), and Carleton (1980) have remarked on the distinctiveness of these genera, and Carleton (1980) suggested that they either represent an early offshoot of the neotomine-peromyscine radiation or are independently derived from North American eumyine stock. Their highly divergent pattern of timing in growth and development is consistent with Carleton's conclusion that their common ancestry with the other neotomine-peromyscines is remote. In this context it would be interesting and potentially informative to compare the de-
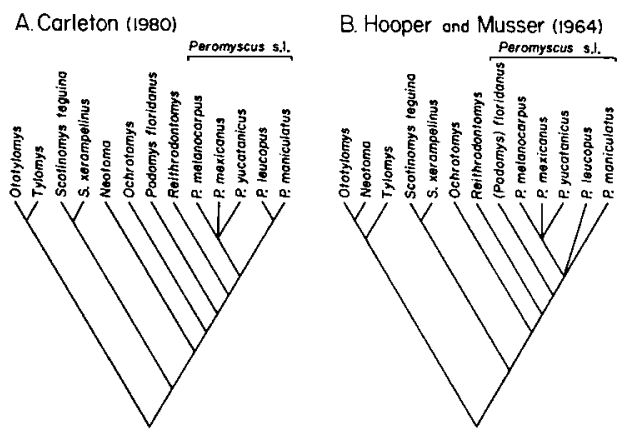

Fig. 9. Hypothesized phylogenies for 14 neotomine-peromyscines from A) Carleton (1980) and B) Hooper and Musser (1964), reduced to include only the taxa studied here. Relationships among Peromyscus spp. are inferred from Hooper's (1968) classification. Square bracket encloses species of Peromyscus sensu lato, after Hooper (1968).

velopmental patterns of Ototylomys and Tylomys with other neotropical cricetines (e.g., the sigmodontines).

Despite the wide range of body sizes and ecological habits represented by the seven species and subspecies of Peromyscus (sensu lato) included in this study, our analysis based on relative timing supports the notion that the genus (along with Podomys) is monophyletic. Inclusion of Podomys in Peromyscus is contrary to the conclusions of Carleton (1980) but in agreement with most previous (Hooper, 1960, 1968) and subsequent (Rogers, 1983) studies.

It is not our intent to imply that these few taxa and characters studied provide a rigorous basis for revising the classification of neotomine-peromyscines. Rather, we compare our results with those derived from more traditional methods to illustrate the information content of data on developmental timing and to emphasize its potential utility in phylogenetic studies. These nine "characters" provide a relatively well resolved picture of interrelationships that is consistent in major outline with previous studies.

An assumption underlying most classification systems, and virtually all attempts at phylogeny reconstruction based on comparative evidence, is that devel- 
opmental programs are conservative and relatively stable-i.e., that morphological similarity reflects similarity in the genetic component of the developmental program. The correspondence between the estimates of general relationships from this study, based on relative timing, and more conventional studies, based on static comparison of adult morphology, is consistent with this general assumption. One advantage of evaluating the ontogeny of morphological traits is that instances in which similarity in adult structure results from different underlying developmental trends (convergence) can be identified (Fig. 5). Furthermore, by evaluating the patterns of morphological change during ontogeny, we may discern the way selection has altered growth patterns to affect the variation that we observe in adult morphology (Guerrant, 1982).

\section{Growth Curves and Allometric Scaling}

The ubiquity of regular size-scaling in interspecific and intraspecific comparisons of morphological structure has long been recognized (e.g., Snell, 1891) and abundantly documented (Huxley, 1932; Gould, 1966, 1975; McMahon, 1973). Laird (1965) elucidated the basis for the frequently observed log-linear allometry of growth in terms of the mathematical relationship between the underlying growth curves of the structures compared. One of the most well known and thoroughly documented allometric relationships in vertebrates is the log-linear scaling of brain size with body size (Jerison, 1973). For comparisons among mammalian taxa spanning even a modest range of body sizes (e.g., primates or rodents), the scaling coefficient for brain size with body size in intergeneric comparisons approximates 0.67 , while in intraspecific comparisons (within or between populations) the coefficient is typically in the range of 0.2 to 0.4 (Jerison, 1973). Lande (1979), in evaluating data on small rodents, suggested that i) the lower coefficient typically observed in intraspecific studies might reflect the

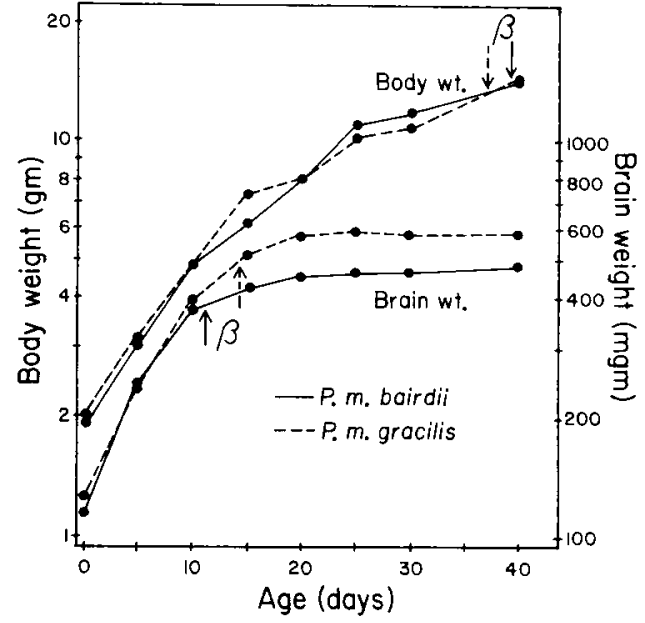

FIG. 10. Postnatal growth in brain weight and body weight for Peromyscus $m$. bairdii and $P$. gracilis showing difference in $\beta$ 's for brain weight. Data from King and Eleftheriou (1960).

genetic correlation between brain size and body size; and ii) the similarity of scaling within and between populations might simply reflect the consequence of selection or random drift acting on body size, with brain size secondarily affected to the degree that it is genetically correlated with body size (see also Leamy and Atchley, 1984). While Lande's inferences are consistent with commonly observed patterns of intraspecific scaling in these features, the proximate mechanism underlying these regular patterns remains unexplained.

Differences in intraspecific scaling of brain size with body size may result from heterochronic shifts in growth patterns (Gould, 1977). For example, the data of Figure 10 represent mean growth curves of brain weight and body weight for laboratory-raised samples of two of the subspecies of Peromyscus maniculatus discussed above. The growth trajectories for body weight are indistinguishable, as is the trajectory for brain weight from birth until about eight days of age. After that age the growth trajectories for brain weight diverge. The allometric relationships between brain weight and body weight from day 10 through day 40 are 


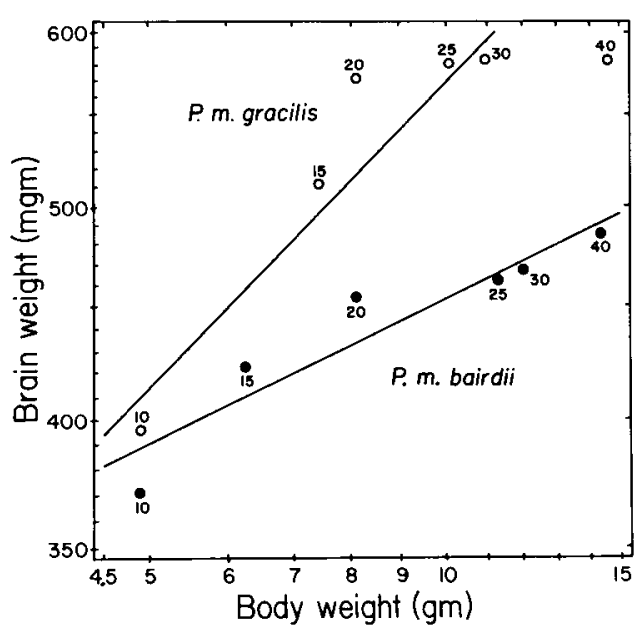

Fig. 11. Log-log plot of postnatal allometry in brain weight vs. body weight for Peromyscus $m$. bairdii (closed circles) and $P$. $m$. gracilis (open circles) from 10 to 40 days of age (labeled points).

plotted in Figure 11. Allometric coefficients for $P$. $m$. bairdii and $P$. $m$. gracilis are 0.21 and 0.37 , respectively, spanning the typical range for intraspecific allometric scaling in these features (Lande, 1979; Gould, 1971). The observed differences in ontogenetic allometry of brain and body weight are a consequence of a difference in the timing of offset in cranial growth. Atchley et al. (1984) have proposed a physiological model to account for such changes in cellular proliferation.

Several inferences can be drawn from this comparison. First, caution must be exercised in deriving conclusions about genetic correlations from data on phenotypic scaling (see Atchley and Rutledge, 1980; Cheverud et al., 1983). The patterns of phenotypic correlations observed in mixed longitudinal series of specimens may simply reflect the age distribution of the sample (Cock, 1966). In natural populations with asynchronous breeding, fluctuating resource availability, and differential size-related mortality, such heterogeneity is to be expected (Myers and Carleton, 1981). In animals with relatively determinant growth (e.g., most mammals) allometric trends may also reflect comparison among adults that cease growing (forward shift in $\beta$ ) at different ages. Scaling identical to that shown in Figure 11 would result from comparison of adult animals whose growth was truncated at various points along the mean trajectories of brain and body weight, simultaneously. Finally, phenotypic correlations may reflect underlying genetic correlations to the extent that these are manifest by changes in the overall rate or timing of growth that affect both characters simultaneously (e.g., pleiotropy).

\section{ACKNOWLEDGMENTS}

We have appreciated, enjoyed, and benefited from discussions with $M$. D. Carleton, W. L. Fink, M. A. Houck, D. J. Klingener, A. G. Kluge, P. Myers, J. L. Patton, G. R. Smith, R. S. Voss, and members of the Museum of Zoology Systematics Discusion Group and the Morphometrics Study Group, concerning various aspects of the methods, results, and interpretions presented here. Michael Carleton generously provided us with his original data on Scotinomys. Financial support from the Division of $\mathrm{Bi}$ ological Sciences and the Museum of Zoology, University of Michigan, and from NSF grants DEB-8011562 (R.E.S. and G. R. Smith) and BSR-8307719 (R.E.S. and F. L. Bookstein) is gratefully acknowledged.

\section{LiteratuRE Cited}

AlberCH, P. 1980. Ontogenies and morphological diversification. Amer. Zool. 20:653-667.

Alberch, P., S. J. Gould, G. F. Oster, AND D. B. WAKE. 1979. Size and shape in ontogeny and phylogeny. Paleobiol. 5:296-317.

Atchley, W. R. 1984. Ontogeny, timing of development, and genetic variance-covariance structure. Amer. Natur. 123:519-540.

Atchley, W. R., B. RiskA, L. A. P. KohN, A. A. Plummer, And J. J. Rutledge. 1984. A quantitative genetic analysis of brain and body size associations, their origin and ontogeny: Data from mice. Evolution 38:1165-1179.

Atchley, W. R., AND J. J. Rutledge. 1980. Genetic components of size and shape. I. Dynamics of components of phenotypic variability and covariability during ontogeny in the laboratory rat. Evolution 34:1161-1173.

BertalanfFy, L. von. 1960. Principles and the- 
ory of growth, pp. 137-260. In W. W. Nowinski (ed.), Fundamental Aspects of Normal and Malignant Growth. Elsevier, Amsterdam, Neth.

BONNER, J. T., AND H. S. HORN. 1982. Selection for size, shape, and developmental timing, pp. 259-276. In J. T. Bonner (ed.), Evolution and Development. Springer-Verlag, N.Y.

Carleton, M. D. 1980. Phylogenetic relationships in neotomine-peromyscine rodents $\mathrm{Mu}-$ ridae) and a reappraisal of the dichotomy within New World Cricetinae. Misc. Publ. Mus. Zool. Univ. Mich. 157:1-146.

Cheverud, J. M. 1982. Phenotypic, genetic, and environmental morphological integration in the cranium. Evolution 36:499-516.

Cheverud, J. M., J. J. Rutledge, and W. R. ATCHLEY. 1983. Quantitative genetics of development: Genetic correlations among agespecific trait values and the evolution of ontogeny. Evolution 37:895-905.

Cock, A. G. 1966. Genetical aspects of metrical growth and form in animals. Quart. Rev. Biol. 41:131-190.

Dawid, I., R. J. Britten, E. H. Davidson, G. A. Dover, D. F. Gallwitz, A. Garcia-Bellido, F. C. Kafatos, S. A. Kauffman, K. Moritz, S. OHNo, J. SCHMIDTKE, AND G. SCHUTZ. 1982. Genomic change and morphological evolution, pp. 19-39. In J. T. Bonner (ed.), Evolution and Development. Springer-Verlag, N.Y.

Dice, L. R., AND R. M. Bradley. 1942. Growth in the deer-mouse, Peromyscus maniculatus. J. Mammal. 23:416-427.

EISEN, E. S. 1975. Results of growth curve analysis in mice and rats. J. Anim. Sci. 42:1008-1023.

FARRIS, J. S. 1970. Methods for computing Wagner trees. Syst. Zool. 19:83-92.

FINK, W. L. 1982. The conceptual relationship between ontogeny and phylogeny. Paleobiol. 8: 254-264.

GouLd, S. J. 1966. Allometry and size in ontogeny and phylogeny. Biol. Rev. Camb. Phil. Soc. 41:587-640.

- 1971. Geometric scaling in allometric growth: A contribution to the problem of scaling in the evolution of size. Amer. Natur. 105:113136.

- 1975. On the scaling of tooth size in mammals. Amer. Zool. 15:351-362.

. 1977. Ontogeny and Phylogeny. Belknap, Cambridge, MA.

GuerRant, E. O., JR. 1982. Neotenic evolution of Delphinium nudicaule (Ranunculaceae): A hummingbird-pollinated larkspur. Evolution 36: 699-712.

Hayden, P., And J. J. Gambino. 1966. Growth and development of the little pocket mouse, Perognathus longimembris. Growth 30:187-197.

Helm, J. D. III. 1973. Reproductive biology of Tylomys and Ototylomys. Ph.D. Diss., Michigan State Univ., East Lansing.

- 1975. Reproductive biology of Ototylomys (Cricetidae). J. Mammal. 56:575-590.
Herbert, J. G., J. F. Kidwell, And H. B. Chase. 1979. The inheritance of growth and form in the mouse. IV. Changes in the variance components of weight, tail length and tail width during growth. Growth 43:36-46.

HoOper, E. T. 1960. The glans penis in Neotoma (Rodentia) and allied genera. Occas. Pap. Mus. Zool. Univ. Mich. 618:1-21.

- 1968. Classification, pp. 27-74. In J. A. King (ed.), Biology of Peromyscus (Rodentia). American Society of Mammalogists, Stillwater, OK.

Hooper, E. T., and M. D. Carleton. 1976. Reproduction, growth and development in two contiguously allopatric rodent species, genus Scotinomys. Misc. Publ. Mus. Zool. Univ. Mich. 151:1-52.

HoOper, E. T., AND G. G. Musser. 1964. The glans penis in neotropical cricetines (Family Muridae) with comments on the classification of muroid rodents. Misc. Publ. Mus. Zool. Univ. Mich. 123:1-57.

HuXley, J. S. 1932. Problems of Relative Growth. Methuen, London, U.K.

JERISON, H. J. 1973. Evolution of the Brain and Intelligence. Academic Press, N.Y.

Jolicoeur, P. 1963. The multivariate generalization of the allometry equation. Biometrics 19: 497-499.

Kidwell, J. F., J. G. Herbert, And H. B. Chase. 1979. The inheritance of growth and form in the mouse. V. Allometric growth. Growth 43: 47-57.

King, J. A., AND B. E. Eleftheriou. 1960. Differential growth in the skulls of two subspecies of deermice. Growth 24:179-192.

Kluge, A. G., AND J. S. Farris. 1969. Quantitative phyletics and the evolution of anurans. Syst. Zool. 18:1-32.

LACKEY, J. A. 1973. Reproduction, growth and development in high-latitude and low-latitude populations of Peromyscus leucopus (Rodentia). Ph.D. Diss., Univ. Michigan, Ann Arbor.

- 1976. Reproduction, growth and development in the Yucatan deer mouse, Peromyscus yucatanicus. J. Mammal. 57:638-655.

LAIRD, A. K. 1965. Dynamics of relative growth. Growth 29:249-263.

LANDE, R. 1979. Quantitative genetic analysis of multivariate evolution, applied to brain:body size allometry. Evolution 33:402-416.

LAYNE, J. N. 1959. Growth and development of the eastern harvest mouse, Reithrodontomys humulis. Bull. Florida State Mus. Biol. Sci. 4: 61-82.

- 1960. The growth and development of young golden mice, Ochrotomys nuttalli. Quart. J. Florida Acad. Sci. 23:36-58.

- 1966. Postnatal development and growth of Peromyscus floridanus. Growth 30:23-45.

. 1968. Ontogeny, pp. 148-253. In J. A. King (ed.), Biology of Peromyscus (Rodentia). 
American Society of Mammalogists, Stillwater, OK.

Leamy, L., AND W. Atchley. 1984. Static and evolutionary allometry of osteometric traits in selected lines of rats. Evolution 38:47-54.

Leamy, L., AND D. Bradley. 1982. Static and growth allometry of morphometric traits in randombred house mice. Evolution 36:1200-1212.

Lessios, H. A. 1981. Divergence in allopatry: Molecular and morphological differentiation between sea urchins separated by the Isthmus of Panama. Evolution 35:618-634.

Lewontin, R. C. 1984. Detecting population differences in quantitative characters as opposed to gene frequencies. Amer. Natur. 123:115-124.

MCMAHON, T. 1973. Size and shape in biology. Science 179:1201-1204.

Morrison, D. F. 1976. Multivariate Statistical Methods. McGraw-Hill, N.Y.

Myers, P., AND M. D. Carleton. 1981. The species of Oryzomys (Oligoryzomys) in Paraguay and the identity of Azara's "Rat sixième ou Rat à Tarse Noir.” Misc. Publ. Mus. Zool. Univ. Mich. 161:1-41.

, and L. L. Master. 1983. Reproduction by Peromyscus maniculatus: size and compromise. J. Mammal. 64:1-18.

RichaRDSON, W. B. 1943. Wood rats (Neotoma albigula): Their growth and development. J. Mammal. 24:130-143.

RICKART, E. A. 1977. Reproduction, growth and development in two species of cloud forest Peromyscus from southern Mexico. Occas. Pap. Mus. Nat. Hist. Univ. Kansas 67:1-22.
RiskA, B., W. R. AtChley, AND J. J. Rutledge. 1984. A genetic analysis of targeted growth in mice. Genetics 107:79-101.

Rogers, D. S. 1983. Phylogenetic affinities of Peromyscus (Megadontomys) thomasi: Evidence from differentially stained chromosomes. J. Mammal. 64:617-623.

SChNell, G. D., T. L. BeST, ANd M. L. KenNedY. 1978. Interspecific morphological variation in kangaroo rats (Dipidomys): Degree of concordance with genic variation. Syst. Zool. 27:3448.

SNELl, O. 1891. Das Gewicht des Gehirnes und des Hirnmantels der Säugetiere in Beziehung zu deren geistigen Fähigkeiten. Sitzungsber. Ges. Morphol. Physiol. München 7:90-94.

SviHLA, A. 1934. Development and growth of deer mice (Peromyscus maniculatus artemisiae). $\mathbf{J}$. Mammal. 15:99-104.

- 1935. Development and growth of the prairie deermouse, Peromyscus maniculatus bairdii. J. Mammal. 16:109-115.

TANNER, J. M. 1963. Regulation of growth in size in mammals. Nature 199:845-850.

TURNer, B. J. 1974. Genetic divergence of Death Valley pupfish species: Biochemical versus morphological evidence. Evolution 28:281-294.

WIRTH, W. O., JR. 1973. Growth and development of Rattus exulans. J. Mammal. 54:189202.

Corresponding Editor: D. Jablonski 